\title{
Teaching Innovation and Practice of the Engineering Graphics Based on SPOC and CDIO Integrated Mode
}

\author{
Songping Chen ${ }^{a}$, Yuze Ren ${ }^{b}$ \\ School of Mechanical and Electrical Engineering, Tan Kah Kee College Xiamen University, \\ Zhangzhou 363105, China. \\ asend_me@126.com, b1505038177@qq.com
}

Keywords: Teaching Innovation, SPOC, CDIO, Flipped Classroom.

\begin{abstract}
SPOC (Small Private Online Course) is a kind of typical course form in Post-MOOC era. CDIO (Conceive-Design-Implement-Operate) engineering teaching concept values the combination of theory and practice, it provides sets of theory and system of engineering education. With the aims of challenging the existing teaching in higher learning institutions, a new teaching method based on SPOC and CDIO integrated mode is proposed in the teaching of Engineering Graphics. It conducts pilot teaching reform of mechanical engineering major to establish and implement SPOC and CDIO integrated mode with application of the flipped classroom pattern into integrated teaching of CDIO engineering education concept based on SPOC online teaching. The practice embodies student-centered teaching and excites students' interest in learning effectively, contribute the interactive relationship between teacher and students, enhances the students' ability to practise and think, efficiently solves teaching-learning disconnection, learning-application disconnection which are existing in the traditional education.
\end{abstract}

\section{Introduction}

CDIO, which stands for Conceive, Design, Implement and Operate, is an approach to the contemporary reform of engineering education [1]. It is based on a few key ideas, the first two being a restatement of the underlying need for reform of engineering education and a set of goals for engineering education. Central to the CDIO approach is a vision for engineering education that includes the use of the engineering lifecycle process as the context of engineering education. The experience at home and abroad shows that the concepts and methods of CDIO are advanced perfectly suited to all aspects of the engineering process of teaching the reform [2][3]. MOOC development today has entered the stage of diversification, which is adapted to the development of higher education in the information age the inevitable result. However, many education researchers worry about whether MOOC can really promote the learning and teaching. SPOC and flipped classroom are hot researches in recent years, the main idea of SPOC is small scale and private online courses and the learners usually are from schools or some students studying online open courses, which is suitable for different teaching objectives, teaching contents, and different levels of learners [4][5].

Engineering graphics as the basic course of mechanical and related professional, is difficult for a number of students whose practical ability and spatial imagination is weaker because the course requires strong practice and spatial imagination. This work will be integrated the concept of CDIO engineering education into the curriculum, and the use of flip classroom teaching method based on the SPOC. The student-centered effective teaching of "learning by doing" and "project-based education and learning" is really realized.

\section{Methodology}

\subsection{Raising Questions.}

Engineering graphics course, like many other subjects, as shown in Fig. 1(a) spoon-feeding methods where students are imposed on some knowledge and their initiative cannot find its place. As 
a highly practical course, Engineering Graphics requires the students do a lot of engineering practice after they familiar with the basic knowledge. However, the spoon-feeding method is just telling the "what", do not tell you or not clear "why", let you go rote, so you know "how to do" is not firm, relies entirely on memory. In order to overcome the soft spot of emphasizing theory and neglecting practice in higher education, enhance the quality of engineering education and solve the shortage of qualified engineering talents. It is very necessary to put forward a student-centered teaching method in the integration of engineering education concept, it is SPOC and CDIO integrated mode mentioned in this article, as shown in Fig. 1(b).
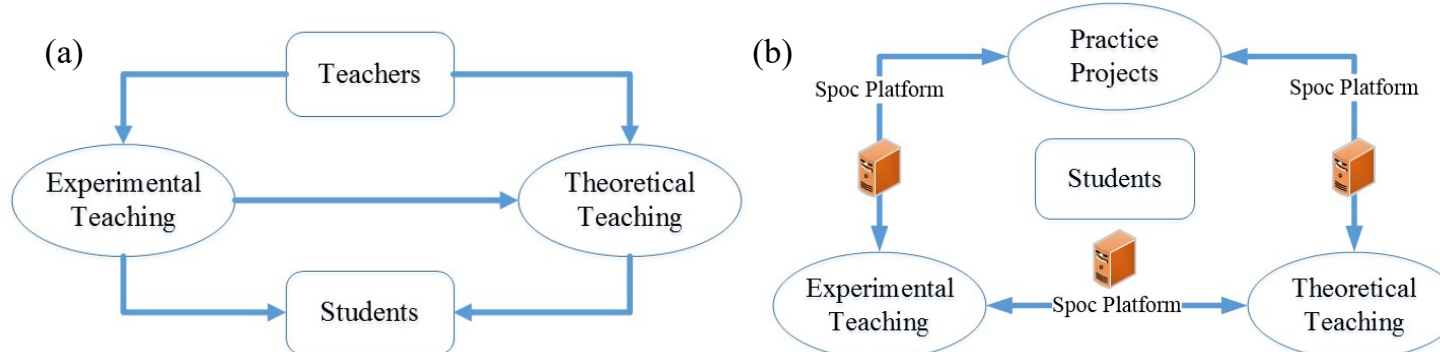

Fig. 1. (a)Spoon-feeding method, (b) SPOC and CDIO integrated mode

\subsection{Design.}

According to the features of Engineering Graphics, flipped classroom teaching mode of Engineering Graphics based on SPOC in CDIO integrated is constructed as shown in Fig. 2. The mode will fall into three modules and four activities of the engineering lifecycle with the time clue: pre-class module, in-class module, post-class module and conceive, design, implement, operate. The mode realizes the knowledge transfer, knowledge construction and knowledge internalization, consolidate and expand through the multi-level task pre-class, typical task in-class and expansion task post-class.

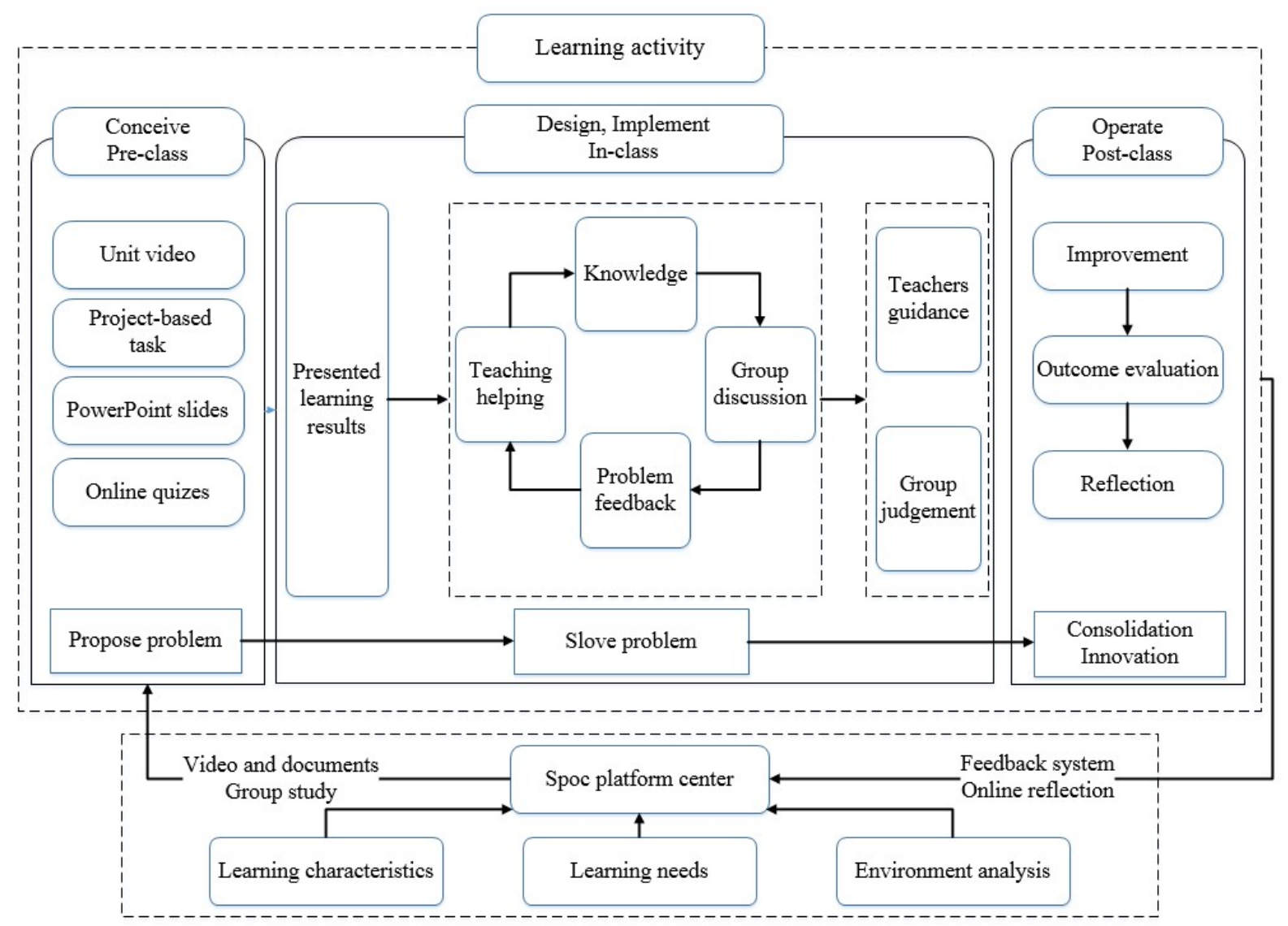

Fig. 2. Engineering Graphics based on SPOC in CDIO integrated teaching mode 


\subsection{Implementation.}

The core of SPOC in CDIO integrated mode is online-offline mixed learning and flipped classroom. As shown in Fig. 2, Pre-class module, teachers use SPOC platform to push learning task for learners, the task includes different kinds of materials e.g. short learning unit videos (less than 10 min.), PowerPoint slides which have a correspondence to videos and quick quizzes, etc. Students must access these materials and complete the quizzes online and feedback their own learning comprehension and questions in learning tasks to upload the platform before the deadline, then teachers check the task list. The number of instructional videos watching record is listed as Fig. 3(a) which can track the students' study process. Fig. 3(b) shows the results of online quizzes, so that we can infer student learning and mastery condition. In-class module, is the process for internalization of knowledge through projects development and solution for problems by students. The instructor will go around the classroom and evaluate students' understanding by raising questions on the materials being offered, and there is collaborative group inquiry and in-depth exchanges between teachers and students, the in-class activities grade is collected during this portion of the class. After the end of each class, all activities result or the progress document should be submitted through the SPOC platform. Post-class module, to help the learners to summarize and improve the knowledge, involves students solving an actual engineering problem in a mini project fashion. Mini projects are often involved topics such as the parts and assembly drawings of the cooperative enterprise. Each mini project is designed such the requirements are clearly indicated, firstly teachers should simply teach the concept and knowledge with question for students before class learning and bring forward project goals so that students can know project task with guideline and then discuss by groups for project development according to project background, during the process of project development, students can communicate with each other and discuss problems to raise questions towards teachers so that teachers answer questions with hints to theory knowledge properly and lead students to think over in-depth question. Students can submit and exhibit their results of design with teacher' s guidance and review to further promote theory.

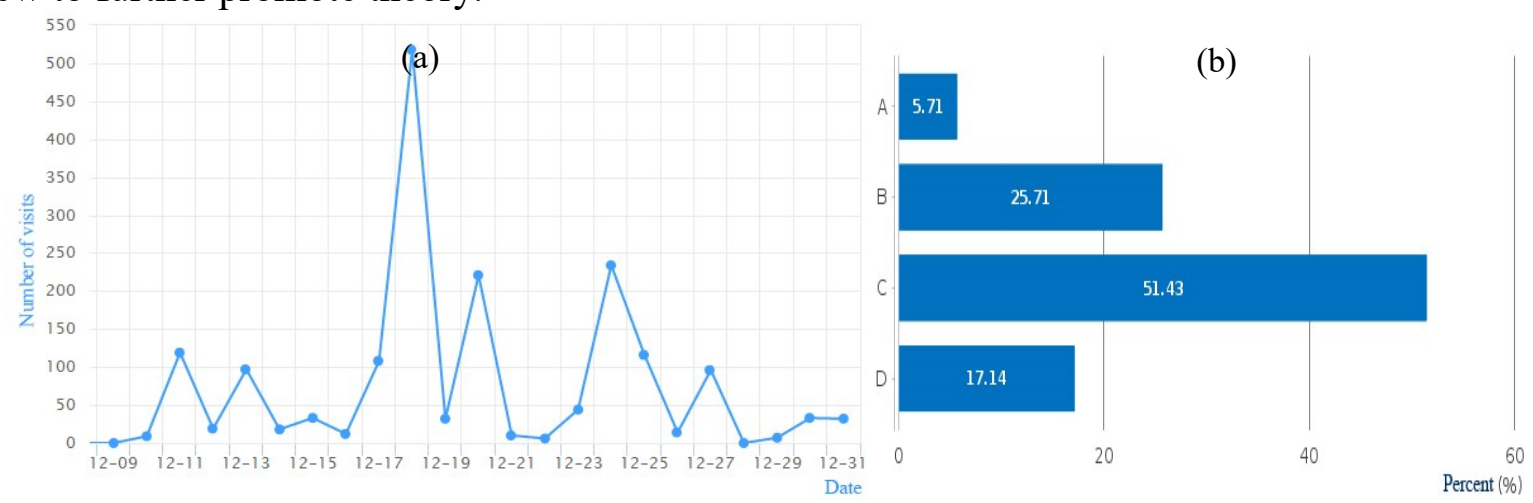

Fig. 3. (a)Number of visits of the SPOC platform, (b) the results of online quize

\subsection{Performance Assessment.}

The traditional way of evaluation is an exam on paper, the quality of teaching and students learning outcomes are evaluated by the marks. CDIO claim the different ability to use assessment in different ways, creates a variety of assessment methods. In order to scientifically and rationally assessment on the abilities of practical ability, communication and communication skills, problem-solving skills, teamwork and innovative ability of students, in the experimental program of the computer specialty appraisal, Engineering Graphics based on SPOC and CDIO integrated teaching mode has the following five aspects of assessment according to the twelve standards of CDIO, technical capability, engineering quality, communication skills, team collaboration and innovation capability. The experimental study focuses on comparing students' performance between the flipped implementation of the Engineering Graphics classes offered in fall 2016 and those offered by the same course in fall 2015 in the traditional spoon-feeding methods. As shown in Fig. 4 the overall performance of the students in fall 2016 was higher than the students in fall 2015. The average marks were 65.5 and 78.3, respectively, with a difference of 12.8 points. Diversification of assessment methods makes the 
evaluation system more complete and reliable, achieving the requirements of the CDIO standards 11 and 12 .

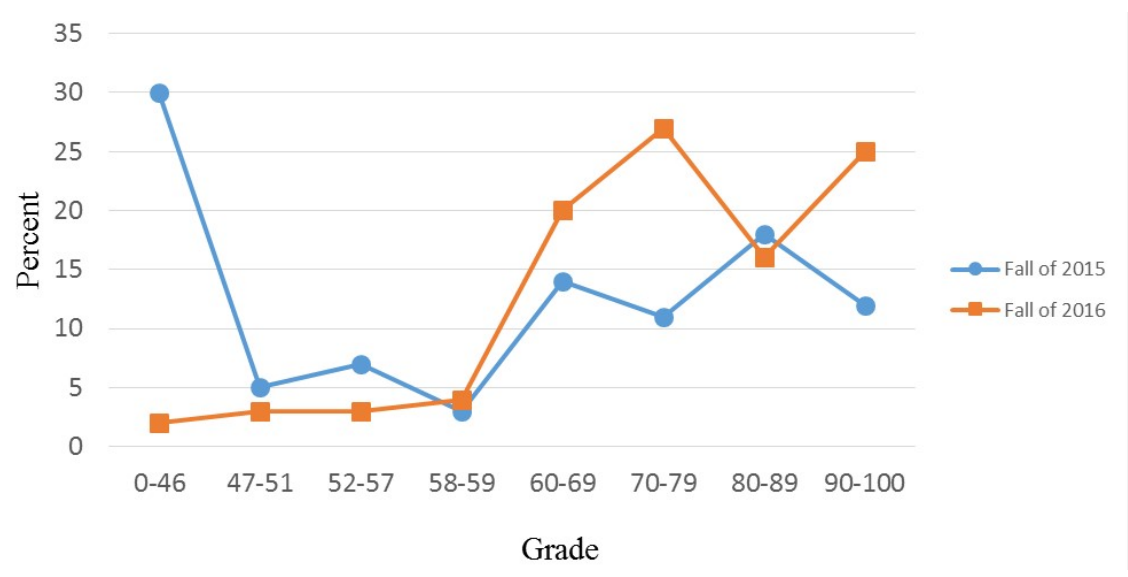

Fig. 4. Distribution of learning achievement

\section{Summary}

Modern mechanical engineering requires the learners not only have a good command of theoretical drawing knowledge, but also practical experience which can only be acquired through engineering practice. Thus, the traditional spoon-feeding method in Engineering Graphics class is increasingly shows its drawbacks. Reform of CDIO is constantly deepened, and MOOC flipped classroom has its advantages. The organic combination of both will strongly overcome the shortcomings of education and cultivate excellent talents. By introducing "student-centered", "learning in doing" and "project-based teaching and learning" based on SPOC and CDIO integrated mode into the Engineering Graphics teaching not only enable students to master the basic professional knowledge and skills, but also enhance the qualities required by the practitioners that plays a greatly active role for the graduates to work in the sustainable development society.

\section{Acknowledgements}

Authors acknowledge financial support from the key projects of the 13th Five-Year Planning of Education Science of Fujian Province (Grant No. FJJKCGZ16-216).

\section{References}

[1]. Information on: Benefits of CDIO, http://www.cdio.org/benefits-cdio.

[2]. Peihua Gu, Yiping Li, Minfen Shen. Training Mode of Innovative Personnel Design-oriented EIP-CDIO. China Higher Education. Vol. 3(2009), p. 47-49.

[3]. Zhiqiang Wang, Ping Cai, Wenfeng Du. Multimedia Applications Basic Courses Teaching Reform based on CDIO. Computer Education. Vo1. 12(2009), p. 137-138.

[4]. M. Zeng, G. Li, Q. Zhou. From MOOC to SPOC: construction of a deep learning model. China Educational Technology. Vol.11(2015), p.28-34.

[5]. Information on: http://www.acasecretariat.be/fileadmin/aca_docs/members/Rolf_Hoffman.pdf. 